Journal of Research in Interprofessional

Practice and

Education

Vol. 3.3

February, 2014

\title{
Interprofessional Collaboration Led by Health Professional Students: A Case Study of the Inter Health Professionals Alliance at Virginia Commonwealth University
}

\author{
Lynn M. VanderWielen, PhD Candidate, MPH; Elizabeth K. Do, MPH; \\ Hadja I. Diallo, RN; Kristen N. LaCoe, PharmD Candidate; Natalie L. \\ Nguyen, PharmD Candidate; Sonal A. Parikh, MD Candidate; Helen Y. \\ Rho, PhD, MD Candidate; Alexander S. Enurah, MD Candidate; Erika K. \\ Dumke, M.Ed.; Alan W. Dow, MD, MSHA
}

\begin{abstract}
Background: Internationally recognized health experts have identified the need for an interdisciplinary approach to meet the healthcare needs of the 21 st century, but academic institutions have been slow to take action. In response, eight health professional students at Virginia Commonwealth University developed a student-led organization, the Inter Health Professionals Alliance (IHPA), to foster a collaborative, interdisciplinary environment among health professional students.

Methods and Findings: The eight students utilized a participatory action research approach to identify 1) an understanding behind the motivation for developing IHPA and 2) the core benefits of group involvement. Four benefits were identified: the development of knowledge and skills, interprofessional networks, professional competence, and role clarity. The case study demonstrated that students can engage in interdisciplinary collaboration from a student-initiated approach and likely improve the care of future patients. Drawing on personal experiences, IHPA board members outline five pieces of wisdom to aid fellow students in the development of student-led interdisciplinary organizations.
\end{abstract}

Conclusions: With enthusiasm and support, students can transform their educational experiences to meet the healthcare needs of the twenty-first century.

Keywords: Interprofessional healthcare; Participatory action research (PAR); Professional education; Healthcare professionals

\section{Introduction}

Interprofessional collaboration and education

All too often healthcare professionals are educated and trained in uniprofessional settings, independent of interdisciplinary collaboration. As these students transition into the healthcare setting as licensed providers, they are expected to work collaboratively and competently on interdisciplinary teams. It is at this point that problems arise, as healthcare providers are merely working side-by-side instead of effectively collaborating and communicating [1]. As a consequence of ineffective teamwork, patients suffer through redundant procedures, miscommunication, and lack of coordinated care [2]. Patients often complain that providers do not coordinate care, causing them to repeatedly provide the same information to different members of the healthcare team [3].

Journal of Research in Interprofessional Practice and Education (JRIPE)

Vol. 3.3

(C) 2014

Corresponding author: Lynn M. VanderWielen Email:yanderwiellm! !@vcu.edu 
2

Inter Health

Professionals Alliance

VanderWielen, Do, Diallo, LaCoe, Nguyen, Parikh, Rho, Enurah, Dumke, \& Dow

Journal of Research in Interprofessional Practice and Education

Vol. 3.3

February, 2014
In 2001, the Institute of Medicine (IOM) released the monumental report titled Crossing the Quality Chasm, drawing the nation's attention to healthcare conditions in the United States. This report outlined a number of underlying explanations for the degrading healthcare system, including the lack of integration of interprofessional teamwork in professional health education and training, which results in uncoordinated and fragmented care delivery [4]. The IOM envisions a healthcare delivery future in which healthcare providers understand the advantage of care continuity and coordination juxtaposed with evidence-based standards and professional cooperation to ensure optimal and reliable care [4]. When an emphasis is placed on effective communication, collaboration, cooperation, and teamwork, these values would surpass the current focus on professional privileges and roles to ensure optimal patient care [4].

Evidence suggests that interprofessional collaboration yields numerous positive outcomes, in both acute and primary care settings [5]. Effective collaboration and team cohesion produces higher patient satisfaction, [2] fewer hospital readmissions, decreased medical errors, improved outcomes among individuals with chronic conditions, and a decreased mortality rate among hospitalized patients [5].

Interprofessional health education takes place when students from multiple professions learn with and from one another and effectively collaborate in order to improve patient outcomes. It also allows students to learn about the training and experiences of other health professionals [5] and to improve perceptions of other healthcare team members [6]. Interprofessional education can play a key role in creating top-performing interdisciplinary teams. Healthcare professionals cannot first be educated in silos and then be expected to work successfully in a truly collaborative environment. Academic institutions should ensure that education occurs in an interprofessional environment that emphasizes communication and collaboration among health professional students.

In 2003, the IOM convened a summit of multidisciplinary healthcare professional leaders to focus specifically on strategies to restructure health professional education, resulting in the report titled Health Professions Education: A Bridge to Quality. This report demands that all health professional students develop five core competencies in order to meet the needs of the healthcare system of the twenty-first century [3]. The IOM identified the most essential competency as working in interdisciplinary teams [3], which consist of members who contribute their discipline-specific skills and knowledge in order to work together to solve a common problem [7]. To ensure continuous and reliable care, healthcare professionals need to utilize teams to cooperate, collaborate, communicate, and integrate care [3]. While experts agree that examples of interprofessional education exist in many institutions, these programs are not standardized, uniformly built into curricula, or consistently evaluated [8].

\section{Virginia Commonwealth University}

Virginia Commonwealth University (VCU) has identified the need for interprofessional scholarship and practice as a core goal, consistent with the University's strategic plan [9]. The VCU Health Sciences Division on the Medical College of Virginia 
3

Inter Health Professionals Alliance

VanderWielen, Do, Diallo, LaCoe, Nguyen, Parikh, Rho, Enurah, Dumke, \& Dow

Campus includes five schools-Allied Health Professions, Dentistry, Medicine, Nursing, and Pharmacy - and an academic health system on a compact 53-acre campus. With over 4,000 students, this setting offers a fertile environment to engage in interdisciplinary education. Although VCU established an Assistant Vice President of Health Science position in 2012 to oversee interprofessional education and lead a centre dedicated to these efforts, many students, aware of the importance of interprofessional collaboration, already sought out opportunities to work with their peers from other health professional schools.

\section{Inter Health Professionals Alliance at VCU}

Interdisciplinary training typically arises from faculty, rather than student-led, initiatives. A student-led approach is surfacing throughout the US among health pro-

Table 1:

\section{Inter Health Professionals Alliance - Board Member Characteristics}

\begin{tabular}{|c|c|c|}
\hline School and Program of Study & \multicolumn{2}{|c|}{$N$} \\
\hline School of Medicine (MD) & \multicolumn{2}{|c|}{$3(37.5 \%)$} \\
\hline School of Medicine (MPH) & \multicolumn{2}{|c|}{$1(12.5 \%)$} \\
\hline School of Nursing (BSN) & \multicolumn{2}{|c|}{$1(12.5 \%)$} \\
\hline School of Pharmacy (PharmD) & \multicolumn{2}{|c|}{$2(25.0 \%)$} \\
\hline School of Allied Health Professions (PhD) & \multicolumn{2}{|c|}{$1(12.5 \%)$} \\
\hline \multicolumn{3}{|l|}{ Race } \\
\hline Black & \multicolumn{2}{|c|}{$2(25 \%)$} \\
\hline Asian & \multicolumn{2}{|c|}{$4(50 \%)$} \\
\hline White & \multicolumn{2}{|c|}{$2(25 \%)$} \\
\hline \multicolumn{3}{|l|}{ Sex } \\
\hline Female & \multicolumn{2}{|c|}{$7(87.5 \%)$} \\
\hline \multirow[t]{2}{*}{ Male } & \multicolumn{2}{|c|}{$1(12.5 \%)$} \\
\hline & $\begin{array}{c}\text { Mean } \\
\text { (years) }\end{array}$ & $\begin{array}{l}\text { Standard } \\
\text { Deviation }\end{array}$ \\
\hline Age & 26 & 3.8 \\
\hline
\end{tabular}

fessional students who recognize interdisciplinary training as a valuable, but lacking, approach in their education [10]. In 2010, six health professional students separately studying medicine, pharmacy, and health services research recognized this gap in their educational experience. In response, they formed Inter Health Professionals Alliance (IHPA), an official student organization to foster interdisciplinary collaboration. The overarching goal of IHPA is to encourage collaboration among health professional students studying at VCU, with a focus on community engagement. The group participates in monthly community health outreach projects and hosts campus sessions that expose student members to a variety of health topics from a diversity of professional perspectives. In addition, IHPA works closely with programs that aim to expose undergraduate, high school, and middle school students to healthcare careers. As of January 2014, IHPA has over 350 member students pursuing doctoral, master's, and baccalaureate health professional degrees within the schools of pharmacy, medicine, dentistry, nursing, social work, engineering and allied health professions, in addition to the dietetic internship program.

The first executive board of IHPA was composed of eight students from the schools of medicine, pharmacy, allied health professions, and nursing, including the departments of social and behavioural health and health administration. Additional demographic data are provided in Table 1 . These eight students brought a wide variety of information, concepts, perspectives, and tools to the IHPA board-an ideal

Journal of Research in Interprofessional Practice and Education

Vol. 3.3

February, 2014 match for interdisciplinary collaboration and research [11]. This article utilizes participatory action research (PAR) to offer a case study of the Inter Health Professionals Alliance at Virginia Commonwealth University and answer the following research questions: 


\section{JRIPE}

4

Inter Health Professionals Alliance

VanderWielen, Do, Diallo, LaCoe, Nguyen, Parikh, Rho, Enurah, Dumke, \& Dow
Journal of Research in Interprofessional Practice and Education

Vol. 3.3

February, 2014
Journal of Research in Interprofessional Practice and Education

- From the student perspective, what are the gained benefits from engaging in interprofessional education and collaboration?

- What are the key strategies to the successful implementation of a student-led interprofessional organization?

\section{Methods}

Participatory action research is a research perspective that requires partnership and involvement among researchers and participants [12]. This approach centres on the experiences of the people most directly affected by the issue in question and encourages a process of reflection [13]. A PAR approach was selected for the case study because all members of the executive board wanted to engage as researchers and participants and to elicit change through the research process, and PAR methodology has been considered aligned with the radical structuralist paradigm [14] of this research. All members of the executive board have basic research training and do not have inherent power differences. The PAR approach aims to maintain this lack of power differences, which could be introduced with other research perspectives. To maintain an egalitarian climate, board members maintained open lines of communication throughout the research process.

Figure 1

\section{Stages of PAR Methodology}

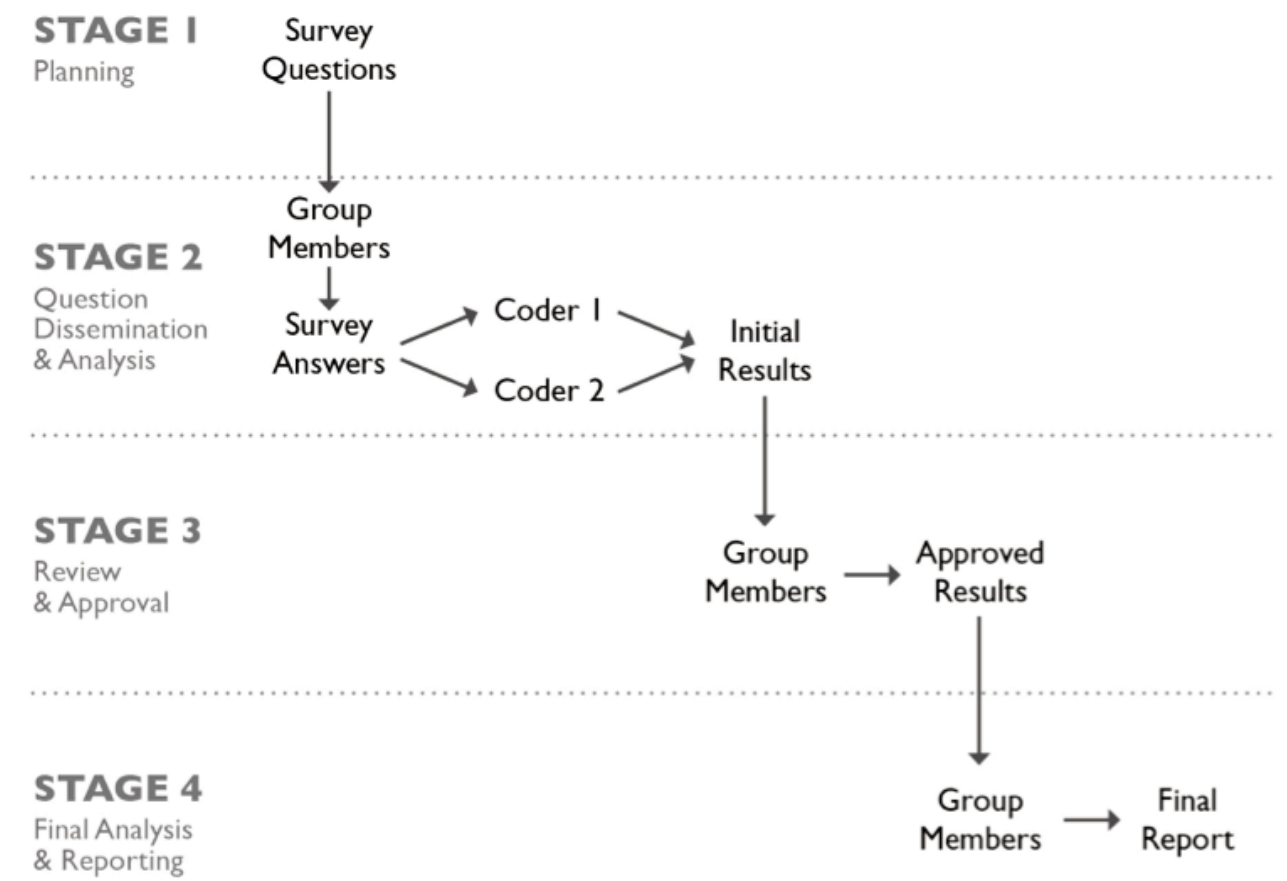


5

Inter Health Professionals Alliance

VanderWielen, Do, Diallo, LaCoe, Nguyen, Parikh, Rho, Enurah, Dumke, \& Dow
Journal of Research in Interprofessional Practice and Education

Vol. 3.3

February, 2014
The research process advanced in four stages, conceptualized in Figure 1. The first stage was the planning stage. Consistent with PAR, all eight board members worked together to decide on the type of data to collect in addition to the change they wanted to elicit through the research process. This included the identification of dissemination strategies necessary to elicit such change. The group decided to collect qualitative data via an online survey tool with intentions of creating a hermeneutic circle, or repeated reflection on the issue, to gain understanding and comprehension of the topic while acknowledging the role of varying experience and perspectives [15] among board members. The goal of a hermeneutic circle was to ensure that coauthors trusted the aggregated responses, and that the responses spoke to their situation and experiences [16]. During the planning stage, board members decided on the first round of questions, displayed in Table 2.

Table 2

\section{Participatory Action Research Survey Questions}

\begin{tabular}{|l} 
Why did you choose to become integrally involved in the Inter Health Professionals Alliance (IHPA) \\
\hline In what ways do you think interprofessional groups, such as IHPA, are important to your education? \\
\hline How do you feel your IHPA experiences will impact your remaining formal education at VCU? \\
\hline How do you feel your IHPA experiences will impact your professional career in the long term? \\
\hline How do you think academic environments, such as VCU, could support interprofessional efforts?
\end{tabular}

The questions were disseminated to all eight board members during the second stage. Responses were analyzed using inductive thematic analysis, which identifies themes linked to the data [17]. Two board members with qualitative training conducted the analysis to defend against introducing single-investigator bias [18]. These two individuals followed the six stages of thematic analysis as outlined in the literature [19]. Once the two analysts individually finalized their analyses, they discussed results to resolve any discrepancies, reaching a final intercoder consensus of $100 \%$.

During stage three, the findings were presented to the remaining six board members. At this time, each of the board members were asked to reflect on their experiences with IHPA to ensure the results were consistent with their lived experiences. All coauthors approved the analysis following one iteration of data collection and analysis.

During stage four, each of the themes found, as a result of steps two and three, were explored in the literature. This process was intended to understand if the resulting themes were consistent with research examining interdisciplinary education and training. Finally, stage four ended with the final manuscript, consistent with the dissemination strategies outlined in stage one.

Prior to data collection, authors consulted with faculty experts regarding the methods used to conduct participatory action research. The process used for this research engaged students as coauthors and does not meet the definitional require- 
6

Inter Health

Professionals

Alliance

VanderWielen, Do, Diallo, LaCoe, Nguyen, Parikh, Rho, Enurah, Dumke, \& Dow
Journal of Research in Interprofessional Practice and Education

Vol. 3.3

February, 2014 ments of human subjects research. Therefore, the study did not require Institutional Review Board approval.

\section{Results}

Board members of the Inter Health Professionals Alliance developed and invested time into the group's creation simply because this collaborative educational approach was not available through other means. Conceptualized in Figure 2, Inter Health Professionals Alliance board members identified four core benefits of interdisciplinary collaboration, including the development of knowledge and skills, professional
Figure 2

Core benefits of extracurricular interprofessional collaboration

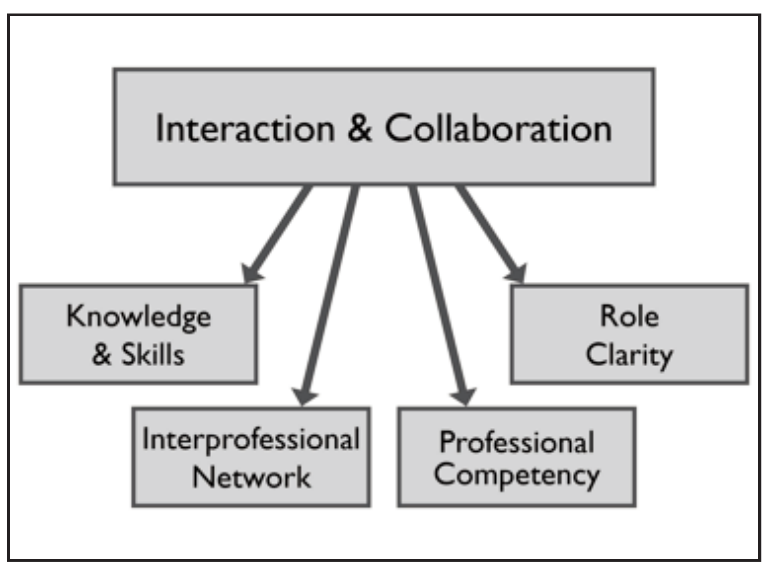
networks, professional competence, and role clarity, that would otherwise be lacking from their formal educational experience.

Knowledge and skills

Patients present with a variety of conditions that one profession alone might not be prepared to remedy [20]. In the United States, patients increasingly present with a variety of comorbidities, inclusive of traditionally non-medical issues [21]. Interdisciplinary education not only exposes individuals to the knowledge and skills of other disciplines, it also allows for contributors to teach the applicable knowledge and skills to other team members. Board members identified knowledge and skills to include both clinical and non-clinical aspects:

IHPA gives us the opportunity for us to learn together and from one another to gain clinical knowledge.

We work together and bring our knowledge and specialties to the table and learn from one another. The educational segments allow us to teach one another through reviewing cases. We brainstorm solutions to tough counselling questions where one answer is not always evident.

Board members identified immediate and future benefits linked to the new knowledge and skills gained from interdisciplinary collaboration.

We are growing in so many ways as healthcare professionals, and the more knowledge we obtain, the better able we are to help our patients now and in the future.

\section{Interprofessional network}

When an individual health professional does not possess the knowledge and skills to address an aspect of a patient's care, he or she might rely on his or her interprofessional network for guidance. Interdisciplinary education allows for students to 
7

Inter Health Professionals Alliance

VanderWielen, Do, Diallo, LaCoe, Nguyen, Parikh, Rho, Enurah, Dumke, \& Dow
Journal of Research in Interprofessional Practice and Education

Vol. 3.3

February, 2014 work on teams composed of emerging healthcare team members. This exposure fosters relationships and networks beneficial to current education and future care. A professional network is a group of professionals that an individual can call on for information and assistance.

As an interdisciplinary student group, IHPA members are able to begin fostering relationships with other emerging health professionals to gain effective communication skills centred on the provision of quality care. This exposure teaches students about the expertise and training of other healthcare professionals and allows for the development of professional ties.

IHPA has allowed me to network with a large number of healthcare professional students that I now consider not only colleagues but friends. I will be able to go to them for advice when I am posed with a question outside of my knowledge base and expertise to provide better care for my patients.

This group offers me a network of professionals that I will be able to work with once we are all practicing in our given fields.

After participating in IHPA, the board members felt they could identify areas beyond their level of expertise to initiate collaboration for the betterment of their patient. Board members started to acquire contacts in their interprofessional network that they would feel comfortable and confident consulting in the future.

\section{Professional competence}

Board members identified growth in professional competence as a result of interdisciplinary collaboration with IHPA. This included appreciation and value of other professional training programs, in addition to an increased appreciation of communication, collaboration, and teamwork to improve patient care $[1,22]$.

I have learned that we each approach the patient from a different viewpoint, from different training, all looking to find the best solution to a patient's ailments, and to provide the best care possible.

Board members described participation in IHPA as a means of minimizing stereotypes and assumptions about each profession's role, and helping students appreciate the knowledge, clinical skills, and training other emerging health professionals receive in their respective curricula. This increased understanding and appreciation for other health professional students permitted the fostering of mutual respect, trust, and improved collaborative efforts.

Being able to work and learn with students from different health schools has really helped me do away with preconceived notions that I have had about the various health disciplines. Before joining IHPA, I had never had any interaction with the other students in the health schools, so I did not know what they were like or what they were learning. But now, after having a chance to work, learn, and 
8

Inter Health

Professionals

Alliance

VanderWielen, Do,

Diallo, LaCoe, Nguyen, Parikh, Rho, Enurah, Dumke, \& Dow
Journal of Research in Interprofessional Practice and Education

Vol. 3.3

February, 2014 socialize together, I have a much better appreciation for what each discipline brings to the healthcare table.

This group has offered insight into the lives and development of other health professionals, and I now place much more value and trust in working together.

Involvement with IHPA provided board members with the opportunity to witness the overlap of professional goals, trust in the training and competence of other health professionals, and collaborate utilizing each other's expertise to provide comprehensive patient care.

\section{Role clarity}

Role clarity, a component of professional competence, refers to the understanding of one's own role and responsibility in relation to that of others within an interdisciplinary team [22]. Board members prodigiously identified role clarity as a core benefit of interprofessional collaboration and an essential element of effective interdisciplinary care. When team members understand their individual and professional role on the team, they are able to fill this role, acknowledge their boundaries, and work synergistically.

Working with IHPA I have realized my importance on the healthcare team as well as the integral role of other healthcare professionals.

The ability to recognize your own profession's contribution and limitations is key to understanding your role on the interdisciplinary team.

Now that I have had experience working with other members of the healthcare team, I believe that I am better able to perform my duties in my role, since I know what my role is. I am more willing and excited to work alongside different members of the patient's team.

Interdisciplinary exposure was also identified to facilitate a broader understanding of healthcare teams and improve educational experiences.

Being able to actually work together at our outreach events allows me to figure out how healthcare teamwork actually functions and what my place is in the grand scheme. Being able to learn what roles the various members have has been a big addition to my education.

Finally, when roles are not uniformly understood, it can create team conflict and can result in misguided competition [23]. The consequences of undefined roles have implications for healthcare outcomes, as energy is exhausted on navigating conflict rather than on patient care.

I have learned that we are all on the same team, we are not competing to show whose role is most important; rather, each person has a vital role in ensuring the best patient outcomes. 
9

Inter Health Professionals Alliance

VanderWielen, Do, Diallo, LaCoe, Nguyen, Parikh, Rho, Enurah, Dumke, \& Dow

Journal of Research in Interprofessional Practice and Education

Vol. 3.3

February, 2014

\section{Discussion}

Within the healthcare setting, professionals are expected to provide high quality care while seamlessly working together. This team-based focus does not align with the uniprofessional training that healthcare professionals typically receive while pursuing their respective degrees. The IHPA was created to provide VCU's health professional students an opportunity to interact and collaborate on an interdisciplinary team to improve teamwork both preceding and following licensure.

Our study results have implications for individuals, academic institutions, and the overall healthcare system. At an individual level, health professional students can participate in interdisciplinary collaboration to develop knowledge and skills, professional networks, professional competence, and role clarity. Individuals who lack these opportunities should consider student-led initiatives to meet their needs. Ideally, students and professionals should engage with interdisciplinary teams early in their education and training, as it takes time to gain the benefits described above [24]. Early exposure to interdisciplinary education while enrolled in academic institutions offers increased opportunities to interact and collaborate with other health professionals. This timeframe is crucial for the development of professional competence and role clarity [2]. Interdisciplinary opportunities, whether faculty or student-led, provide essential exposure that is currently limited in academic settings.

Many academic institutions, including VCU, have identified interdisciplinary education as a key component of health professional education [9]. Although students are responsible for individual learning, academic institutions have the opportunity to offer students a variety of experiences that will ultimately mold them as professionals. Consequently, academic institutions should recognize and embrace the benefits of interdisciplinary education and champion this approach to improve professional training. When the student-initiated approach is complemented with the faculty-led perspective, more students will have a greater opportunity to benefit from such experiences.

Although the literature on interdisciplinary education does not reach a uniform consensus regarding all of the benefits of interdisciplinary teams at the level of the healthcare system [24,25], a number of research studies have discussed how such teams positively impact patient care in both inpatient and outpatient settings. Interdisciplinary teams are thought to improve primary care because they promote a team-based focus requiring a shared responsibility of the health of the patient [26]. This team focus requires shared responsibilities, accompanied by trust [27], mutual respect, and open communication between fellow team members [28-31]. Open coordination of care and a team-based focus allow for the identification of gaps and redundancies that often negatively affect quality of care [4]. For these reasons, interdisciplinary teams have been demonstrated to improve quality [32], clinical outcomes [2], patient satisfaction [2], and patient safety [33]. Experiences that instill the value of clinical collaboration early in education may provide the strongest platform for future team-based care.

Participatory action research utilizes a methodological approach to understand a problem and subsequently enact change by involved stakeholders. The research 
10

Inter Health Professionals Alliance

VanderWielen, Do, Diallo, LaCoe, Nguyen, Parikh, Rho, Enurah, Dumke, \& Dow
Journal of Research in Interprofessional Practice and Education

Vol. 3.3

February, 2014 team hopes that their lived experiences encourage individuals and organizations to embrace interdisciplinary teams and education, even if these experiences are less formal, student-led programs. In the words of one of the board members, "Why not get an early start on what we will practice in the future? It only makes perfect sense to start our interdisciplinary training now, especially when the resources are right at our fingertips."

\section{Summary of collected wisdom}

One of the implications of this study is that students can successfully take the initiative to engage in interdisciplinary collaboration from a student-led approach. The IHPA can serve as a framework for health professional students who seek to improve knowledge and skills, interprofessional networking, professional competence, and role clarity. We offer the following five suggestions to optimize the success of other student groups, outlined in Table 3.

\section{Table 3}

\section{Summary of collected wisdom for building successful student-led interdisciplinary teams within academic institutions}

\section{Engage your team around a common goal: \\ Success hinges upon members' shared views.}

\section{Choose advisors carefully:}

Connection with faculty aids in member recruitment and information dissemination, thereby ensuring sustainability. Interdisciplinary focus can be lost if housed with one advisor; it may be best to create an advisory panel.

Consider leadership roles in the group and make them representative:

Have rules set in place and decide if rotations are necessary to maintain an interdisciplinary focus.

\section{Design projects to utilize a range of professionals:}

Team members should be able to recognize how they directly contribute to the project.

\section{Remember that conflicts may arise:}

Education systems with unidisciplinary curricula can easily create misconceptions about different professions. Embrace such conflict as learning opportunities to strengthen professional competence and role clarity.

First, engage around a common goal [34]. Board members felt that the success of IHPA hinged on community involvement, the provided patients benefits, and reaching goals through interdisciplinary collaboration. Second, seek faculty representation from all member schools. This connection with faculty can often aid in establishing school support, recruiting new members, disseminating group information, and ensuring sustainability. Interdisciplinary groups can quickly lose their interdisciplinary focus if housed within one school. Therefore, seek advisors from all member schools to create an advisory panel. The IHPA has utilized an office outside of the five health sciences schools to serve as the main advisory role, in addition to formal relationships with faculty members from individual schools. Third, consider leadership roles in the group and be sure the governing board represents all member schools. The IHPA has requirements to rotate board positions between school repre- 
11

Inter Health

Professionals

Alliance

VanderWielen, Do,

Diallo, LaCoe,

Nguyen, Parikh,

Rho, Enurah,

Dumke, \& Dow
Journal of Research in Interprofessional Practice and Education

Vol. 3.3

February, 2014 sentatives to ensure that one member school does not dominate these positions. Fourth, optimize interprofessional collaboration by designing projects that require a range of professionals. Team members should be able to recognize how they directly contribute to the project. The IHPA activities utilize both clinical and non-clinical skills to provide a holistic approach to healthcare. For example, during outreach events clinical students take blood pressures, whereas non-clinical students may talk to clients about available community resources. Finally, when engaging in collaborative activities, understand that conflicts will arise that are likely the result of a siloed educational system. A variety of clinical skills can be accomplished by a number of professional students; for example, dental, medical, nursing, and pharmacy students all learn to take blood pressure readings. These students should work together to foster collaboration and support professional competency through an equal division of duties and responsibilities. Teams that have shared roles and responsibilities are more likely to succeed [27].

\section{Limitations and future studies}

This case study describes the experience of eight students at one university, and may not represent the opinions of all health professional students. These students have had overwhelmingly positive experiences with IHPA and worked well together as a group, and this team dynamic may not represent the experiences of others engaging in similar interdisciplinary groups. However, the continued growth of the IHPA suggests many students find value in these undertakings and that these results may have broader implications. Finally, results offer a cross-sectional understanding of interdisciplinary education. Future studies should embrace a longitudinal design to understand how student-led interdisciplinary education changes students with time and how these experiences and attitudes unfold among participating individuals.

\section{Conclusion}

A number of internationally recognized organizations such as the Institute of Medicine, World Health Organization, and the Interprofessional Education Collaborative identify the need to develop efficient and sustainable interdisciplinary education opportunities for emerging health leaders. These educational experiences can foster collaborative teamwork in healthcare settings to improve the quality of care provided in the US and abroad. In contrast to many other interprofessional education programs, the Inter Health Professionals Alliance at Virginia Commonwealth University developed a student-led approach to collaboration. A participatory action research methodology identified four core benefits of interdisciplinary collaboration and involvement, including the development of knowledge and skills, interprofessional networks, professional competence, and role clarity. Both academic institutions and health professional students should embrace student-initiated approaches to interdisciplinary education while simultaneously incorporating interdisciplinary opportunities for students in a faculty-led manner. Many health professional students are ready and eager to embrace interdisciplinary education to improve the lives of our future patients. 
Inter Health Professionals Alliance

VanderWielen, Do, Diallo, LaCoe, Nguyen, Parikh, Rho, Enurah, Dumke, \& Dow
Journal of Research in Interprofessional Practice and Education

Vol. 3.3

February, 2014

\section{Acknowledgments}

The authors would like to thank the Virginia Oral Health Coalition and the DentaQuest Foundation for their ongoing support of interprofessional education, and Joshua Jurrens for conceptualization and design of manuscript figures.

\section{References}

1. Interprofessional Education Collaborative Expert Panel. (2011). Core competencies for interprofessional collaborative practice: Report of an expert panel. Washington, DC: Interprofessional

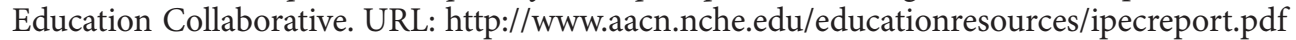
[October 7, 2013].

2. Grumbach K., \& Bodenheimer T. (2004) Can health care teams improve primary care practice? JAMA: Journal of the American Medical Association, 291(10), 1246-1251.

3. Greiner, A., \& Knebel, E. (Eds.). Health Professions Education: A Bridge to Quality. National Research Council. (2003). Washington, DC: National Academies Press.

4. National Research Council. (2001). Crossing the Quality Chasm: A New Health System for the 21st Century. Institute of Medicine. Washington, DC: National Academies Press.

5. The World Health Organization. (2010). Framework for action on interprofessional education \& collaborative practice. Geneva, Switzerland.

6. Ateah, C.A., Snow, W., Wener, P., MacDonald, L., Metge, C., Davis, P., Fricke, M., Ludwig, S., \& Anderson, J. (2011). Stereotyping as a barrier to collaboration: Does interprofessional education make a difference? Nurse Education Today, 31(2), 208-213.

7. Hall, P., \& Weaver, L. (2001). Interdisciplinary education and teamwork: A long and winding road. Medical Education, 35(9), 867-875.

8. Abu-Rish, E., Kim, S., Choe, L., Varpio, L., Malik, E., White, A.A., Craddick, K., Blondon, K., Robins, L., Nagasawa, P., Thigpen, A., Chen, L.L., Rich, J., \& Zierler, B. (2012). Current trends in interprofessional education of health sciences students: A literature review. Journal of Interprofessional Care, 26(6), 444-451.

9. Virginia Commonwealth University, Office of the Provost. Quest for Distinction: Discovery, Impact,

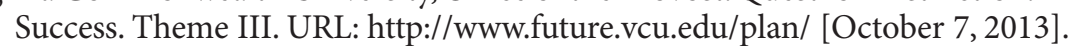

10. VanderWielen, L., Enurah, A., Osburn, I., LaCoe, K., \& Vanderbilt, A. (2013). The development of student-led interprofessional education and collaboration. Journal of Interprofessional Care. (0), $1-2$.

11. Committee on Facilitating Interdisciplinary Research, National Academy of Sciences, National Academy of Engineering, Institute of Medicine. (2004). Facilitating Interdisciplinary Research. Washington, DC: The National Academies Press.

12. Padgett, D. (2012). Qualitative and Mixed Methods in Public Health. Thousand Oaks, CA: SAGE Publications, Inc.

13. Baum, F., MacDougall, C., \& Smith, D. Participatory action research. (2006). J Epidemiol Community Health, 60(10), 854-857.

14. Goodley, D., \& Lawthom, R. (2005). Epistemological journeys in participatory action research: Alliances between community psychology and disability studies. Disability \& society, 20(2), $135-151$.

15. Kezar, A. (2000). The importance of pilot studies: Beginning the hermeneutic circle. Research in Higher Education, 41(3), 385-400.

16. Burrell, G., \& Morgan, G. (1979). Sociological Paradigms and Organisational Analysis. Burlington, VT: Ashgate.

17. Patton, M.Q. (2002). Qualitative Research \& Evaluation Methods (Third ed). Thousand Oaks, California: Sage Publications, Inc.

18. Cassady, D., Castaneda, X., Ruiz Ruelas, M., Miller, Vostrejs, M., Andrews, T., \& Osorio, L. (2012). Pandemics and vaccines: Perceptions, reactions, and lessons learned from hard-to-reach Latinos and the H1N1 campaign. Journal of Health Care for the Poor and Underserved, 23(3), $1106-1122$.

19. Braun, V., \& Clarke, V. (2006). Using thematic analysis in psychology. Qualitative Research in Psychology, 3(2), 77-101.

20. Zucchero, R.A., Hooker, E.A., Harland, B., Larkin, S., \& Tunningley, J. (2011). Maximizing the impact of a symposium to facilitate change in student attitudes about interdisciplinary teamwork. Clin Gerontol, 34(5), 399-412. 
13

Inter Health

Professionals

Alliance

VanderWielen, Do,

Diallo, LaCoe,

Nguyen, Parikh,

Rho, Enurah,

Dumke, \& Dow
Journal of Research in Interprofessional Practice and Education

Vol. 3.3

February, 2014
21. Committee on the Future Health Care Workforce for Older Americans, Board on Health Care Services (HCS), Institute of Medicine (IOM). (2008). Retooling for an aging America: Building the health care workforce. Washington, DC: The National Academies Press.

22. Hallin, K., Kiessling, A., Waldner, A., \& Henriksson, P. (2009). Active interprofessional education in a patient based setting increases perceived collaborative and professional competence. Medical Teacher, 31(2), 151-157.

23. Wittenberg-Lyles, E., Oliver, D.P., Demiris, G., Baldwin, P., \& Regehr, K. (2008). Communication dynamics in hospice teams: Understanding the role of the chaplain in interdisciplinary team collaboration. Journal of Palliative Medicine, 11(10), 1330-1335.

24. Kilgore, R.V., \& Langford, R.W. (2009). Reducing the failure risk of interdisciplinary healthcare teams. Critical Care Nursing Quarterly, 32(2), 81-88.

25. Zwarenstein, M., Goldman, J., \& Reeves, S. (2009). Interprofessional collaboration: Effects of practice-based interventions on professional practice and healthcare outcomes. Cochrane Database Systematic Reviews 3(CD000072).

26. Margotius, D., \& Bodenheimer, T. (2010). Transforming primary care: From past practice to the practice of the future. Health Affairs, 29(5), 779-784.

27. Chesluk, B.J., \& Holmboe, E.S. (2010). How teams work or don't in primary care: A field study on internal medicine practices. Health Affairs, 29(5), 874-879.

28. Clements, D., Dault, M., \& Priest, A. (2007). Effective teamwork in healthcare: Research and reality. Healthcare Papers, 7(1), 26-34.

29. Blackmore, G., \& Persaud, D.D. (2012). Diagnosing and improving functioning in interdisciplinary health care teams. Health Care Management, 31(3), 195-207.

30. Youngwerth, J., \& Twaddle, M. (2011). Cultures of interdisciplinary teams: How to foster good dynamics. Journal of Palliative Medicine, 14(5), 650-654.

31. San Martin-Rodriguez, L., Beaulieu, M.D., D’Amour, D., \& Ferrada-Videla, M. (2005). The determinants of successful collaboration: A review of theoretical and empirical studies. Journal of Interprofessional Care, 19(1), 132-147.

32. Oandasan, I., Baker, R., Barker, K., Bosco, C., D’Amour, D., Jones, L., Kimpton, S., Lemieux-Charles, L., Nasmith, L., San Martin Rodriguez, L., Tepper, J., \& Way, D. (2006). Teamwork in healthcare: Promoting effective teamwork in healthcare in Canada. Ottawa: Canadian Health Services Research Foundation.

33. Taber, D.J., Pilch, N.A., McGillicuddy, J.W., Bratton, C.F., Chavin, K.D., \& Baliga, P.K. (2012). Improved patient safety and outcomes with a comprehensive interdisciplinary improvement initiative in kidney transplant recipients. American Journal of Medicine Quarterly, 28(2), 103-112.

34. Buljac-Samardzic, M., Dekker-van Doorn, C.M., van Wijngaarden, J.D.H., \& van Wijk K.P. (2010). Interventions to improve team effectiveness: A systematic review. Health Policy, 94(3), 183-195. 